\title{
TERSINE MÜHENDISLIIK ÇALIŞMALARINDA SOLIDWORKS SCAN TO 3D MODÜLÜ KULLANARAK TARAMA DATASINDAN KATI MODEL OLUŞTURULMASI
}

\author{
İsmet ÇELİK*, Ebru IŞIK
}

Kütahya Dumlupınar Üniversitesi, Mühendislik Fakültesi, Makine Mühendisliği Bölümü, Kütahya, Türkiye

\begin{tabular}{l}
\hline Anahtar Kelimeler \\
\hline Tersine Mühendislik, \\
Bilgisayar Destekli Tasarım, \\
3 Boyutlu Tarama.
\end{tabular}

3 Boyutlu Tarama.

\begin{abstract}
Öz
Tersine mühendislik; CAD dataları olmayan parçaların üretilmesi, uzun süre kullanım sonucu yıpranan ya da hasar gören parçaların tamiri ya da yeniden üretilmesi, CAD dataları mevcut parçalar üzerinde yenilik veya düzeltmeler yaparak yeni parçaların ortaya çıkarılması, seri üretimine başlanacak parçaların kalite kontrolünde yararlanılması gibi amaçlarla kullanılmaktadır. Tersine mühendislikten makine, arkeoloji, tıp, diş hekimliği, tekstil ve daha birçok bilim dalı yararlanmaktadır. Tersine mühendislik işlemleri genellikle tersine mühendislik için özel hazırlanan programlar ile yapılmaktadır. Günümüzde endüstride tasarım için yaygın kullanılan CAD programları ile de tersine mühendislik işlemleri belirli bir seviyeye kadar yapılabilir hale gelmiştir. Ancak endüstride bu CAD programlarının tersine mühendislik için de kullanılabildiği pek fazla bilinmemektedir. Bu çalışma kapsamında endüstride tasarım için yaygın kullanılan SolidWorks programının tersine mühendislik için kullanılabileceği gösterilmek istenmiştir. Araştırmada endüstriyel parça öncelikle optik tarama cihazıyla taranmıştır. Taramadan elde edilen veriler nokta bulutu ya da STL (Standard Triangle Language) formatında bilgisayar ortamına aktarılmıştır. CAD programının tersine mühendislik modülünde veriler düzenlenmiş ve parçanın katı modeli oluşturulmuştur.
\end{abstract}

\section{CREATING SOLID MODELS WITH SCANNED DATA BY USING SOLIDWORKS SCAN TO 3D MODULE AT REVERSE ENGINEERING}

\author{
Keywords \\ Reverse Engineering, \\ Computer Aided Design, \\ 3D Scanning.
}

\begin{abstract}
Reverse engineering is used for many purposes; as a way to make new parts when CAD data is not available, to repair parts which is damaged cause of long therm use or reconstructing, to add new features or re-arrangements on existing parts which have already CAD data, to benefit from quality control of parts which will be started to serial production. Machinery, archaeology, medicine, dentistry, textile and more branches of sciences can benefit from reverse engineering. Reverse engineering operations are usually made by softwares which is designed specially for reverse engineering. In present days, reverse engineering process can be done up to a level with widely used CAD programmes. But in the industry it is not known enough that CAD programmes can be also used for reverse engineering. In this study, it has been wanted to show that solidwork programme -which is widely used in industry- can be used for reverse engineering. In this search, firstly, industrial part has been scanned with an optical scanner. And then data, obtained from scanning process, has been transferred to computer environment as STL (Standard Triangle Language) format. S ubsequently, data -which has been transferred to the computer environment before- has been arranged and solid model of the part has been created at reverse engineering module of CAD programme.
\end{abstract}

\section{Alıntı / Cite}

Çelik, İ., Işık, E., (2021). Tersine Mühendislik Çalışmalarında Solidworks Scan to 3d Modülü Kullanarak Tarama Datasından Katı Model Oluşturulması, Mühendislik Bilimleri ve Tasarım Dergisi, 9(2), 606-615.

\footnotetext{
* İlgili yazar / Correyasponding author: ismet.celik@dpu.edu.tr, +90 274-433-4178
} 


\begin{tabular}{l|l|l}
\hline Yazar Kimliği / Author ID (ORCID Number) & \multicolumn{3}{|l}{ Makale Süreci / Article Process } \\
\hline İ. Çelik, 0000-0002-6564-0880 & Başvuru Tarihi / Submission Date & 09.11 .2020 \\
E. Işık, 0000-0002-6328-8166 & Revizyon Tarihi / Revision Date & 08.03 .2021 \\
& Kabul Tarihi / Accepted Date & 01.05 .2021 \\
& Yayım Tarihi / Published Date & 20.06 .2021 \\
\hline
\end{tabular}

\section{Giriş (Introduction)}

Tersine mühendislik fiziksel modellerden geometrik modellerin oluşturulması, mevcut bir parçanın yeniden tasarlanması ve boyutlarının analizi için sistematik bir yaklaşımdır (Eren vd., 2018). Tersine mühendislikte amaç, ortada hiçbir CAD model yok iken, bir nesnenin gelecek çalışmalarda kullanılmak üzere başarılı bir şekilde 3B CAD modelini oluşturmaktır (Şahin vd., 2017). Tersine mühendislik işlemlerinde ilk olarak belirlenen bir ürün optik ya da lazer tarama cihazlarıyla taranarak elde edilen veriler tarama cihazı ile entegre çalışan bir programa aktarılır. Bu programda kayıt altına alınan nokta bulutu verileri bilgisayar ortamına aktarılır. Bilgisayar ortamında nokta bulutu verileri düzenlenir. Düzenlenmiş nokta bulutu verilerinden ürünün katı modeli oluşturulur. Katı modeli oluşturulan ürün imal edilmek istenirse hızlı prototipleme ya da klasik yöntemlerle imal edilerek tersine mühendislik işlemleri tamamlanır.

Tersine mühendislik, ürünün üretim süreçleri de dahil olmak üzere özelliklerinin ve ürünü oluşturan bileşenlerin birbirleri ile olan ilişkisinin analiz edilmesidir (Chikofsky vd.,1990: İșbilir F. vd.'den,2018).

Tersine mühendislik bir nesnenin kopyasını ya da fonksiyonel olarak yeniden konstrüksiyonunu yapmak için bir ölçme, analiz ve test süreci olarak tanımlanabilir (Önçağ vd., 2017). Bu yaklaşım bir ürünün yüzey verilerinin elde edilmesini, bu veriler ile CAD modelinin oluşturulmasını ve sonrasında imalatını kapsayan bir süreçtir.

Tersine mühendislikten makine, arkeoloji, tıp gibi birçok alanda faydalanılır. Makine endüstrisinde CAD datası mevcut olmayan ya da karmaşık şekilli parçalar tekrar üretilmek istendiğinde parçaların yeniden tasarımını yapmak uzun zaman alacağından tersine mühendislik yaklaşımıyla mevcut parçanın CAD dataları hızlı bir şekilde oluşturulabilir. Örneğin; helis dişlilerin diș profili karmaşık yapılı olduğundan tasarımı zahmetlidir ve tasarım uzun zaman almaktadır. Şahin ve arkadașları karmașık șekle sahip hasarlı helis dișlisinin tekrar olușturulması çalışmasında tersine mühendisliğin sunduğu kolaylıklardan dolayı tersine mühendislik yaklaşımından faydalanmışlardır (Şahin vd.,2017). Tersine mühendislik yaklaşımı arkeoloji alanında dijital arşivlemede kullanılır. Tarihi eserler 3 boyutlu tarama cihazlarıyla taranarak eserlerin CAD dataları elde edilir, ürün hasar gördügünde daha önce tersine mühendislik ile elde edilen datalar yardımıyla eserlerin hasar gören parçaları aslına uygun olarak onarılabilir. Bu kapsamda Bursa Büyükşehir Belediyesi, olası bir felakete karşı Bursa Ulu Cami ve diğer tarihi yapıları lazer taraması ile bilgisayar ortamına aktarmaktadır. Tıp alanında protez ve implant imalatında kişiye özel tasarım oluşturulurken tersine mühendislikten faydalanılır. Kişiye özel tasarımlar hastanın daha hızlı bir şekilde iyileşmesini sağlar ve hastanın hayat kalitesini artırır. Çelebi ve arkadaşları çalışmalarında kişiye özel implant tasarımı yapmak için tersine mühendislik yaklaşımı kullanmışlardır. Kafatası hasar görmüş bir hastanın bilgisayarlı tomografisinden kafatasının .stl verilerini elde etmişlerdir. Kafatasının dijital verileri ile hasarlı bölüm için hastaya özel implant tasarlamışlardır. (Çelebi vd.,2017)

Tersine mühendislik işlemi temel olarak aşağıdaki adımlarla gerçekleştirilir (Sarı, 2019). İlk aşama tarama veya diğer adıyla dijitalleştirmedir. Model yüzeyi optik ya da lazer tarayıcılar yardımıyla taranır. Optik tarama cihazlarıyla küçük çapta delik içermeyen ve yüzeyi üzerinde daha az detay bulunan parçalarda tercih edilirken; lazer tarama cihazları daha kompleks parçaların taranmasında tercih edilir. Model yüzeyinden alınan veriler nokta topluluğu şeklindedir bu nokta topluluğuna nokta bulutu denir. Alınan veriler nokta bulutu veya noktaların örüntülendiği mesh yapısı şeklinde kaydedilir. Tarama cihazları ile entegre çalışan yazılımlar doğrudan mesh yapıyı da çıktı olarak verebilir. Bu durumda CAD ortamına meshli veri aktarılabilir. CAD programına aktarılan stl veya ply formatındaki tarama verilerinin mesh yapıları üzerinde düzenlemeler yapılabilir. Stl (Standard Triangle Language) veri formatı parça yüzeyinin, noktaların üçgenlerle birleştirildiği yüzey tanımlamasıdır. Her üçgen üç nokta ve yüzeyinin bir yön vektörü ile tanımlandığı bir yapıdadır. Normal vektör ve noktalar $\mathrm{x}, \mathrm{y}$ ve $\mathrm{z}$ koordinatlariyla temsil edilir (Manmadhachary vd., 2016).

Tarama verisi CAD programlarında nokta bulutu ya da mesh yapı olarak açlabilir. Açılan dosyalar CAD modeli yapısı olmayıp üzerinde herhangi bir CAD işlemi yapılamaz. Verinin işlenerek düzenlenmesi ve CAD katı modeline dönüştürülmesi gerekir. Bu işlemler tersine mühendislik kapsamında yapılır. 


\section{Kaynak Araștırması (Literature Survey)}

Tersine mühendislik alanında yapılan çalışmalardan bazıları aşağıda yer almaktadır.

Sarı, çalıșmasında hali hazırda kullanılan statik üst ekstremite ortezlerinin (el, kol, ön kolda ișlev kaybı ya da işlevde azalma olduğunda kullanılan yardımcı eleman) ciltte zedelenme, kontraktürler, enfeksiyon vb. komplikasyonlara neden olduğuna değinmiştir. Bu komplikasyonları en aza indirmek ya da ortadan kaldırmak amacıyla statik üst ekstremite ortezlerinin tersine mühendislik yaklaşımı kullanılarak tasarımı ve 3B yazıcı vasıtasıyla üretimini amaçlamıștır. Çalışmasının sonucunda her hastaya özel hafif, zarif, su ile temas edebilen, terlemeyen, koku yapmayan, bakteri ve mikrop oluşumunun yaşanmadığı, rahat ve konforlu ortezler elde etmiştir (Sarı, 2019).

Demir çalışmasında, uyluk (femur) ve kaval (tibia) kemik doku kaybı olan bir hastanın tomografik görüntüsünden faydalanılarak kişiye özel diz protezi ve protezin takılmasında kullanılacak kemik kesi kılavuz parçalarının tasarımı ve üretimi için kemik geometri dokusunun sayısallaştırıcı programlar kullanılarak 3B model görünümünün elde edilmesine çalışmıştır. Tasarımı ve teknik çizimi imkansız gibi görünen insana ait prototip uyluk kemiğinin 3B model görünümü ve teknik çiziminin tersine mühendislik yöntemiyle nasıll elde edilebileceği örnekle açıklanmıştır (Demir, 2018).

Önçağ ve arkadaşları sanayide kullanımı fazla olan mekanik parçaların yeniden tasarım ya da onarımı için tersine mühendislik yöntemi kullanan literatür çalışmalarını incelemiş ve bir iş akışı oluşturmuş̧lardır. Oluşturdukları iş akışını bir turboşarj dirseği üzerinde uygulamıșlardır. Tersine mühendislik yaklaşımıyla elde ettikleri katı modeli birebir ölçekte 3D yazıcılarda basmışlardır. Çalışmada kullanılan örnek parçayı akış şemasına göre değerlendirmişlerdir. 3D yazıcı kullanımının tersine mühendislik uygulamalarının standart bir parçası haline gelebileceği sonucuna ulaşmışlardır (Önçağ vd., 2018).

Çetinel, çalışmasında iki ya da üç boyutlu nesnelerin ölçümünü fotoğraf verileri ile yapan bir teknik olan Fotogrametri yöntemini kullanılarak tersine mühendislik çalışmaları yapmıştır. Fotogrametrik yöntemi için gerekli yazılım kodlarını oluşturmuş ve mevcut kodları derlemiştir. Farklı uygulamalar için adapte edilebilecek esnek ve basit algoritmalar geliștirmiștir. Tezde araștırılan teorik konular ve uygulamaların pratikte nasıl gerçekleștirilebileceği, gerçek bir örnek ile gösterilmiştir (Çetinel, 2008).

Kaplan, çalışmasında, bakım çalışmaları yapılan bir hidroelektrik santralinde bulunan su türbini çark kanatlarının onarımında tersine mühendislik işlemlerinden faydalanmıștır. Karmaşık yapıya sahip parçaların klasik ölçüm aletleriyle (kumpas, mikrometre vb.) teknik bilgilerinin çıkarılmasının olanaksız olduğunu belirtmiştir. Tersine mühendislik yönteminde ise optik tarayıcılar yardımıyla gerekli teknik veriler toplanıp tersine mühendislik programlarıyla kolayca bu veriler işlenebileceğinden Kaplan çalışmasında tersine mühendislik yöntemini seçmiştir. Tersine mühendislik yöntemi kullanarak su türbini çark kanatlarının onarımını gerçekleștirilmiştir (Kaplan, 2016).

Literatür çalışmaları incelendiğinde klasik yöntemlerle üretilen ortezlere nazaran daha kullanışlı kişiye özel statik üst ekstremite ortezlerinin tersine mühendislik yöntemi ile tasarımı ve 3 boyutlu yazıclarla üretimi, tersine mühendislik yöntemiyle kişiye özel diz protezi ve protezin takılmasında kullanılacak kemik kesi kılavuz parçalarının tasarımı, mekanik parçaların tersine mühendisliğine yönelik iş akış şemasının oluşturulması konularında yukarıda da açıklanan çalışmalar tersine mühendislik yazılımları kullanılarak yapılmıştır.

Bu makalede sunulan çalışmada ise tersine mühendislik için özel olarak tasarlanmış (Geomagic, Space Claim vb. gibi) programlarda yaplan tersine mühendislik uygulamalarının, tasarım için kullanılan 3D CAD programlarında yapılabilirliği araştırılmıştır. Endüstriyel olarak seçilen örnek parçaların taraması yapılmış ve taranan parçalardan elde edilen nokta bulutunun tasarım için yaygın kullanılan SolidWorks programında tersine mühendislik işlemleri uygulanarak katı modelinin oluşturulması gerçekleștirilmiştir.

\section{Materyal ve Yöntem (Material and Method)}

Bu çalışmada bir otomobile ait yağlama borusu optik tarama ile taranmış ve elde edilen tarama datası SolidWorks'un tersine mühendislikte kullanılan modülü ile işlenerek CAD katı modeli oluşturulmuştur. Şekil 1'de kullanılan optik tarama cihazı ve model taraması verilmiştir. Tarama datası nokta bulutu ya da tarama cihazlarının yazılımlarından elde edilen üçgen mesh yapı (stl formatı) şeklinde olabilir. Modelin nokta bulutu Şekil 2(a) ve 'stl' yapıdaki görünümü Şekil 2(b)'deki gibidir. 


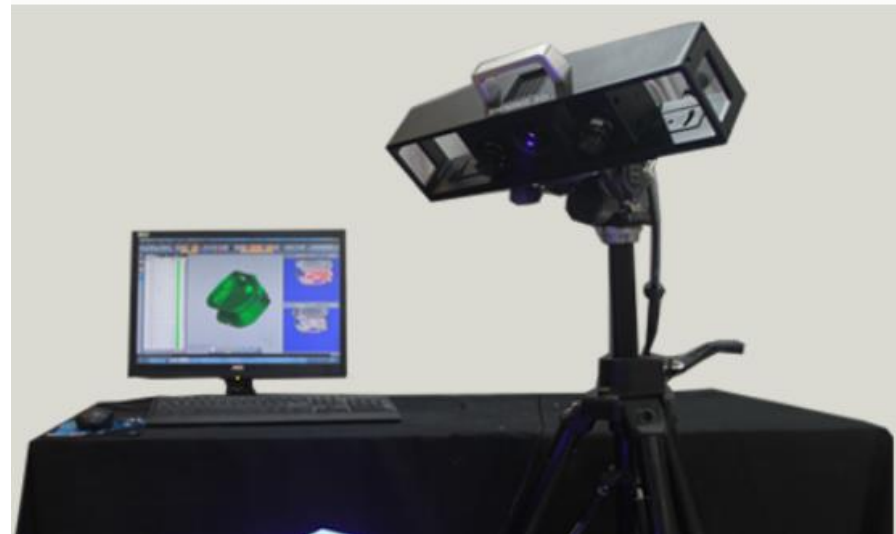

Şekil 1. Modelin optik taramayla taranması (Scanning of the model with optical scanner)

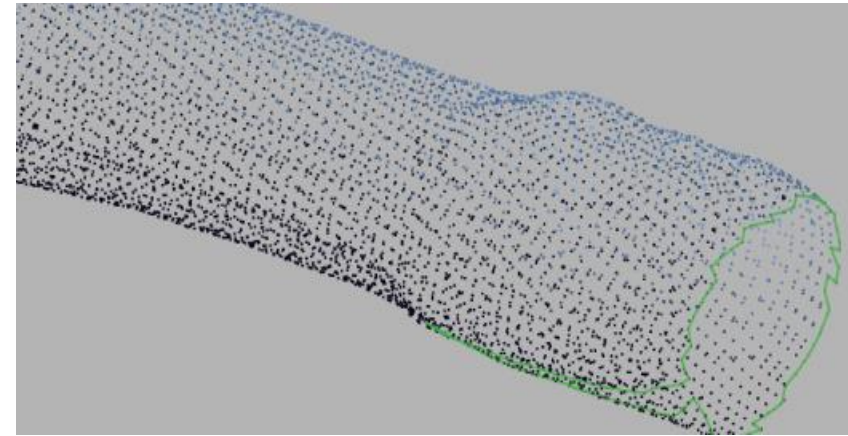

(a)

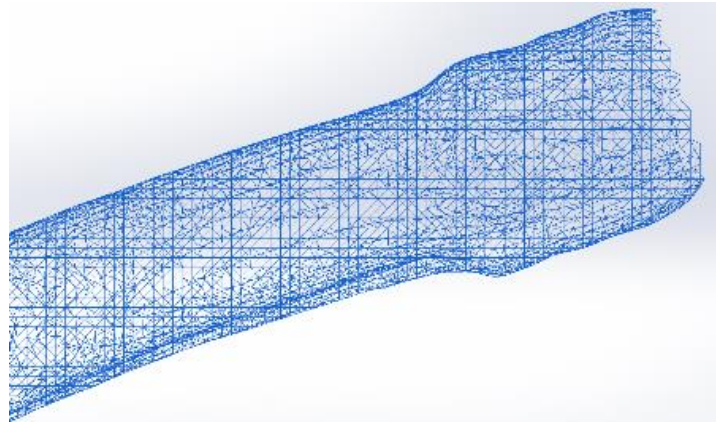

(b)

Şekil 2. Optik tarama ile elde edilen nokta bulutu (a) 'Stl' yapı (b) (Point cloud obtained by optical scanning (a) and stl structure (b))

Parçanın taranmasından elde edilen tarama datası verisi SolidWorks programına Scan to 3D modülü yardımıyla aktarılır. Şekil 3'de SolidWorks ortamında açılan mesh yapı görülmektedir.

\subsection{Tersine Mühendislikte Kullanılan Scan to 3D Eklentisi (Scan to 3D Add-in Used in Reverse Engineering)}

Programa aktarılan meshli yapı Şekil 4'te ve Scan to 3D eklentisi seçenekleri Şekil 5'te verilmiștir.Seçenekler Mesh Hazırlık Sihirbazı, Mesh Düzenleme, Eğri Sihirbazı, Yüzey Sihirbazı ve Sapma Analizi olmak üzere 5 modül içerir. Bu modüllerin fonksiyonları ve parçaya uygulanan işlemler aşağıda açıklanmıştır.

\section{Mesh Hazırlık Sihirbazı (Mesh Prep Wizard)}

Mesh Hazırlık Sihirbazı üç boyutlu tarama cihazıyla taranıp CAD programına aktarılan nokta bulutunu/mesh yapıyı düzenlemek için çeşitli seçenekler sunar. Mesh yapıyı düzenleme seçenekleri sırasıyla; Mesh Oryantasyonu, Dışarıdan Veri Çıkarma, Basitleştirme, Düzleştirme ve Boşluk Doldurmadır.

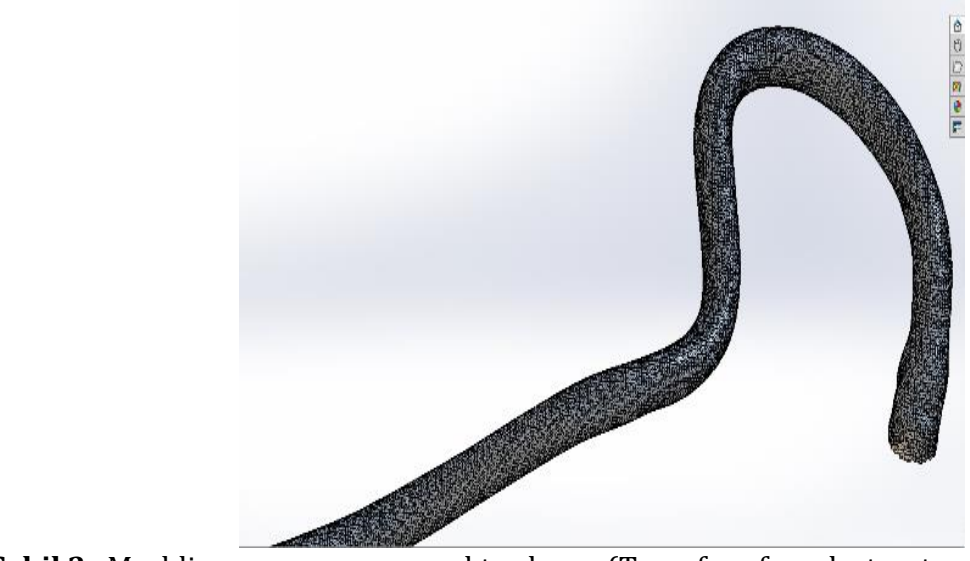

Şekil 3. Meshli yapının programa aktarılması (Transfer of mesh structure into programme) 


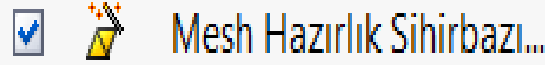 \\ Q Mesh Düzenleme.... \\ च is Eğri Shirbazl... \\ v Yüzey Sihirbazı....

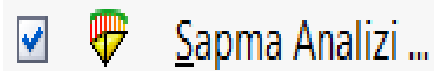

Şekil 4. Scan to 3D modülleri (Modules of Scan to 3D)

Nokta Bulutu Oryantasyonu/Mesh Oryantasyonu komutu nokta bulutunun/mesh yapının yerleşiminin x, y, z eksenlerinde hareket ettirme veya döndürme gibi seçenekleri ile değiștirilmesine yardımcı olur. Dışarıdan veri çıkarma komutuyla; model çevresinde veya üzerinde, hatalı taramadan kaynaklı, düzgün elde edilemeyen veriler temizlenir. Örneğin Şekil 5 (b)'de yağlama borusunun baş kısmında yer alan veriler, hatalı taramadan kaynaklı düzgün elde edilememiş veri barındırdığından bu bölüm dışarıdan veri çıkarma komutuyla düzgün bir şekilde kesilerek tasarımın kalanıyla uyumlu hale getirilmiştir. Şekil 5(a)'da dışarıdan veri çıkarma penceresi, Şekil 5(b)'de tarama hatası olan bölge, Şekil 5(c)'de ise bu bölgenin silinmesi verilmiștir. Parça üzerinde ya da parça etrafında istenmeyen veriler bu pencerede bulunan kutu, kement, çokgen gibi seçim araçlarıyla seçilir yine aynı pencerede bulunan sil komutuna tıklanarak temizlenir. Hatalı bir işlem yapıldığında pencerede bulunan geri alma komutuna tıklanarak işlem iptal edilir.

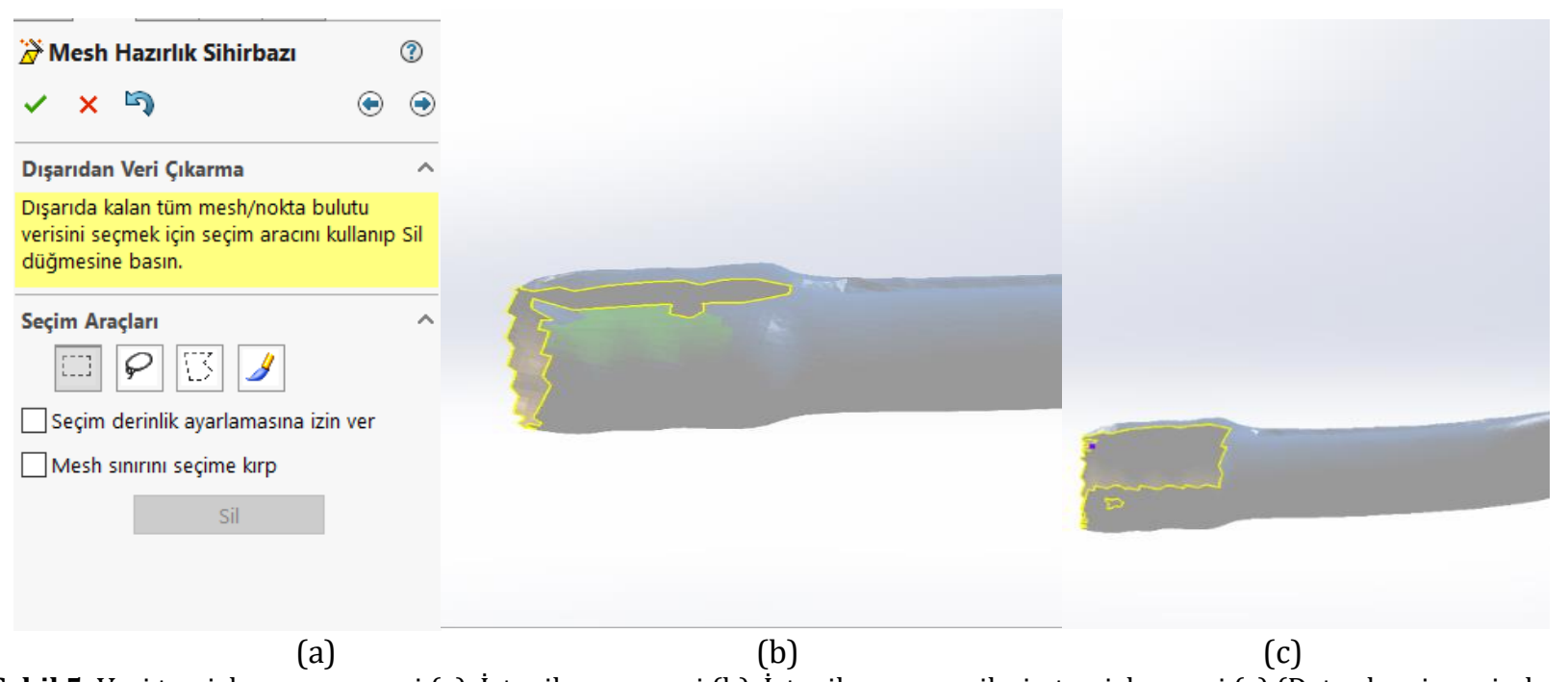

Şekil 5. Veri temizleme penceresi (a), İstenilmeyen veri (b), İstenilmeyen verilerin temizlenmesi (c) (Data cleaning window (a), Unwanted data(b), Cleaning of unwanted data(c) )

Mesh boyutun küçültülmesi model üzerinde yapılacak işlemleri hızlandırır ancak mesh boyutunu küçültmek bazen model üzerinde șekil bozukluklarına neden olmaktadır. Șekil 6(a)'da basitleștirme penceresi, Șekil 6(b)'de mesh boyutu azaltılmadan üçgen yapıların görüntüsü, Şekil 6(c)'de mesh boyutu azaltıldığında oluşan şekil bozukluğu görülmektedir. Bu çalışmada mesh boyutunu küçültmek şekil bozukluğuna neden olduğundan mesh boyutu küçültme işlemi yapılmamıştır. Basitleştirme penceresinde global basitleştirme ve hedef mesh boyutu olmak üzere iki komut bulunur. Global basitleștirme komutunda bulunan seçim ile ilk mesh boyutunun azaltma oranı yüzde olarak belirlenir program tarafından otomatik olarak mesh boyutu azaltılır. Hedef mesh boyutu komutunda ulaşılmak istenen son mesh boyutu elle girilir ve enter tuşuna basılır. 


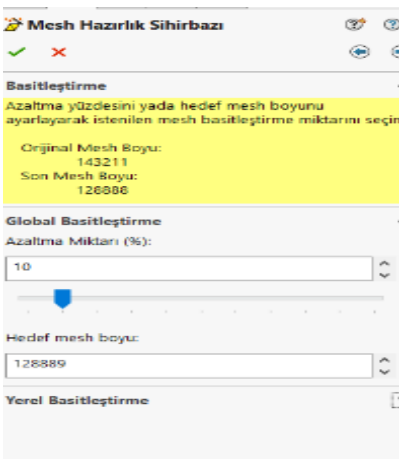

(a)

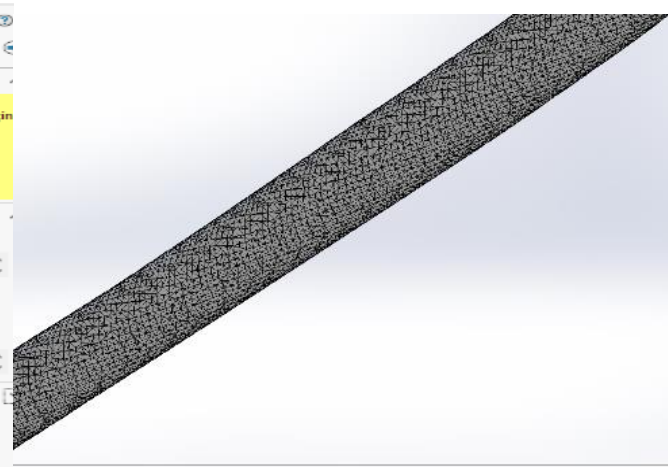

(b)

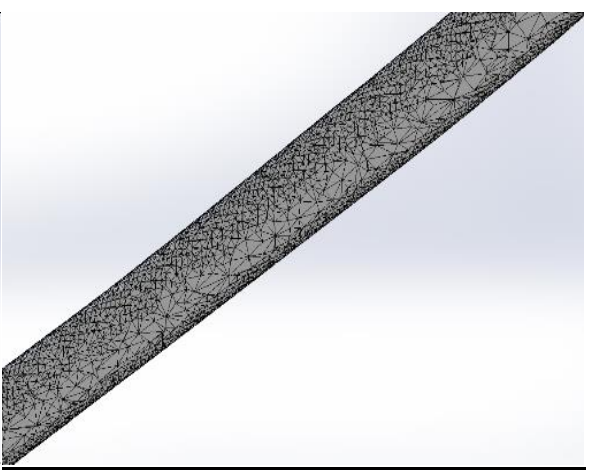

(c)

Şekil 6. Basitleștirme penceresi (a), Mesh boyutu değiştirilmeden modelin görüntüsü (b), Mesh boyutu azaltıldığında modelde oluşan şekil bozukluğu (c) (Simplification window (a), View of the model before mesh scale cahnged (b), Shape deformity of the model when mesh scale is reduced (c))

Taranan modelin yüzeyi pürüzlü ise pürüzsüzleștirme ișlemi yapmak daha sonra yapılacak ișlemleri kolaylaștırır. Bu çalışmada model yüzeyi pürüzsüzleştirme işlemi gerektirmemektedir ancak model sınırlarında girintili çıkıntılı bir yüzey görülmektedir. Sınırlardaki bu pürüzlülüğü gidermek için mesh hazırlık sihirbazının dördüncü penceresi olan pürüzsüzleștirme seçeneğindeki sınır pürüzsüzleştirme modülü kullanılmıș, sınırlar daha pürüzsüz bir yapıya dönüștürülmüştür. Şekil 7(a)'da düzleştirme penceresi, Şekil 7(b)'de pürüzsüzleștirme işleminden önceki sınırların görüntüsü ve Şekil 7(c)'de pürüzsüzleștirme işlemi sonrası modelin görüntüsü verilmiștir. Düzleștirme penceresinde global pürüzsüzlük, yerel pürüzsüzlük ve sınır pürüzlülüğü olmak üzere üç komut bulunur. Global pürüzsüzlük komutu modelin tüm yüzeylerinde pürüzsüzleștirme işlemi yapmak için kullanılır. Global pürüzsüzlük komutunda bulunan hassasiyet değeri arttırılıp azaltılarak modelin pürüzsüzlük değeri değiştirilir, hassasiyet değerine bağlı olarak program modelin pürüzsüzlük değerini otomatik değiștirir. Yerel pürüzsüzlük komutunda pürüzsüzleştirmek istenilen bölge kutu, kement veya çokgen seçim araçlarıyla seçilir komutun altında bulunan hassasiyet değeri ayarlanarak model üzerinde belli bir bölgenin pürüzsüzlük değeri belirlenir. Sınır pürüzsüzlügünde komutun altında bulunan hassasiyet değeri ayarlanarak program tarafından otomatik sınır düzenlemeleri yapılır.

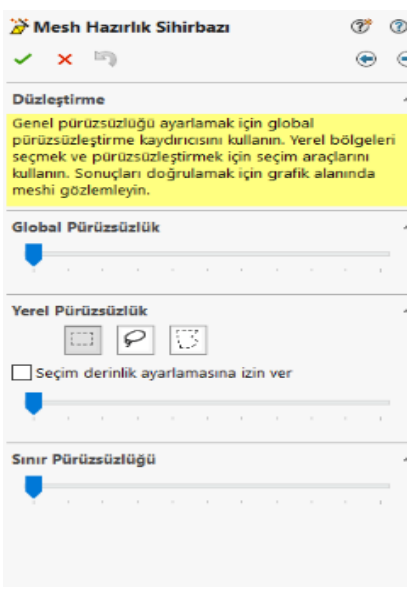

(a)

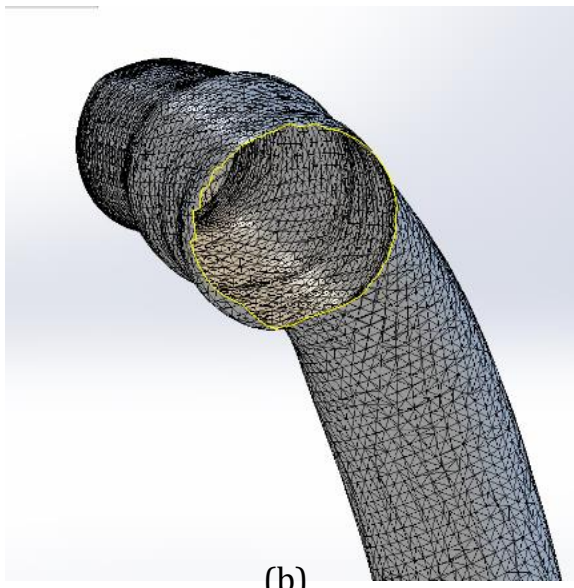

(b)

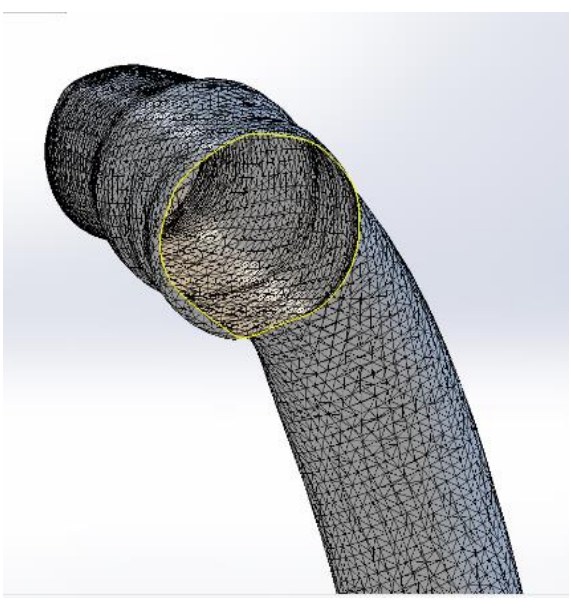

(c)

Şekil 7. Düzleștirma penceresi (a), Pürüzsüzleştirme işlemi öncesi sınırlar(b),Pürüzsüzleştirme işlemi sonrası sınırlar(c) (Smoothing property manager (a), Borders before smoothing process (b), Borders after smoothing process (c))

Mesh hazırlık sihirbazında açılan beșinci pencere delik doldurmadır.Mesh hazırlık sihirbazının son aşamalarında model üzerinde doldurulması gerekli boşluklar doldurulur. Şekil 8(a)'da delik doldurma penceresi, Şekil 8(b)'de boşluk doldurma işlemi öncesi modelin görüntüsü, Şekil 8(c)'de boşluk doldurma işlemi sonrası modelin görüntüsü verilmiştir. Program model üzerindeki boşlukları otomatik olarak belirler. Program tarafından numaralandırılmış boşluklar delik doldurma penceresinde açılır. Doldurulması istenmeyen boşluklar seçilip silinir. Silinmeyen boşluklar bir sonraki pencereye geçildiğinde program tarafından otomatik doldurulur. 


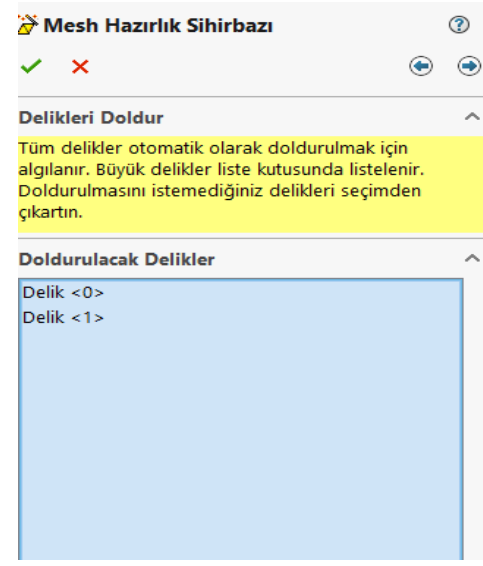

(a)

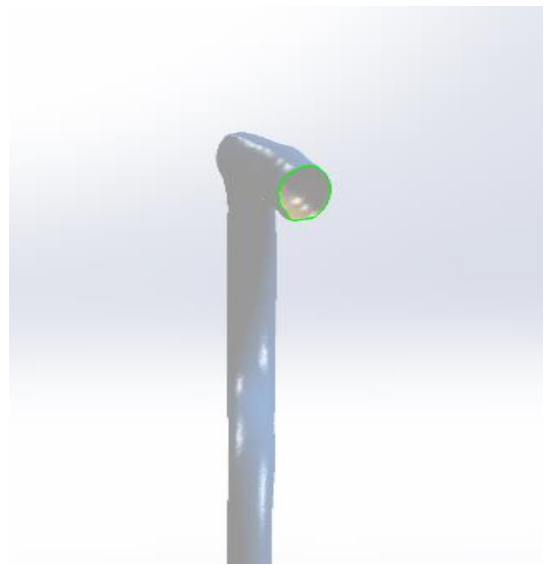

(b)

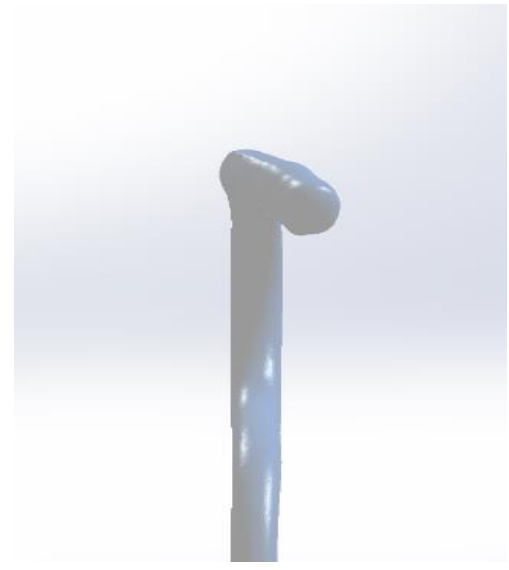

(c)

Şekil 8. Delik doldurma penceresi (a), Boşluk doldurma öncesi modelin görünümü (b), Boşluk doldurma sonrası modelin görünümü (c) (Fill holes property manager (a), View of the model before filling (b), View of the model after filling (b))

\section{Mesh Düzenleme (Surface Wizard Property Manager)}

Scan to 3D eklentisindeki bu modül ile asıl mesh yapı $\mathrm{x}, \mathrm{y}$ ya da $\mathrm{z}$ yönünde öteleme uzaklığı ve döndürme açısı belirlenerek taşınabilir ve ölçeklendirme yapılabilir. $\mathrm{x}, \mathrm{y}$ veya $\mathrm{z}$ yönünde öteleme uzaklığı ve döndürme açısı girilerek asıl mesh ile kopya arasındaki uzaklık ve açı belirlenir.

\section{Eğri sihirbazı (Curve Wizard Property Manager)}

Eğri sihirbazı modülü kullanılarak modelin iki boyutlu üç boyutlu çizimleri ve istenilen düzlem ile model üzerinden iki boyutlu üç boyutlu kesit çizgileri alınır. Bu modülün kesit ve sınır olmak üzere iki komutu vardır. Kesit komutu tıklandığında altta açılan pencereye kesit alınmak istenilen düzlem ve kesit alınmaya başlamak istenilen nokta girilir. Kullanıcı tarafından belirlenen düzlem ve başlangıç noktasına uygun olarak program iki boyutlu, üç boyutlu kesit çizgilerini oluşturur. Sınır komutu tıklandığında program otomatik modelin sınırlarını belirler ve iki boyutlu, üç boyutlu sınır çizgilerini otomatik oluşturur.

Yapılan uygulamada kesit komutu ile eğri sihirbazı kullanılmıştır. CAD modeli oluşturabilmek için gereken yüzeylere düzlemler atanarak modelden kesitler alınmıștır. Düzlem oluşturma işleminde unsurlar modülündeki referanslar komutundan düzlem seçilir. Açılan pencerede düzlem oluşturmak için gerekli üç nokta belirlenir ve düzlem oluşturulur. Şekil 9'da düzlem oluşturma işlemi verilmiştir.

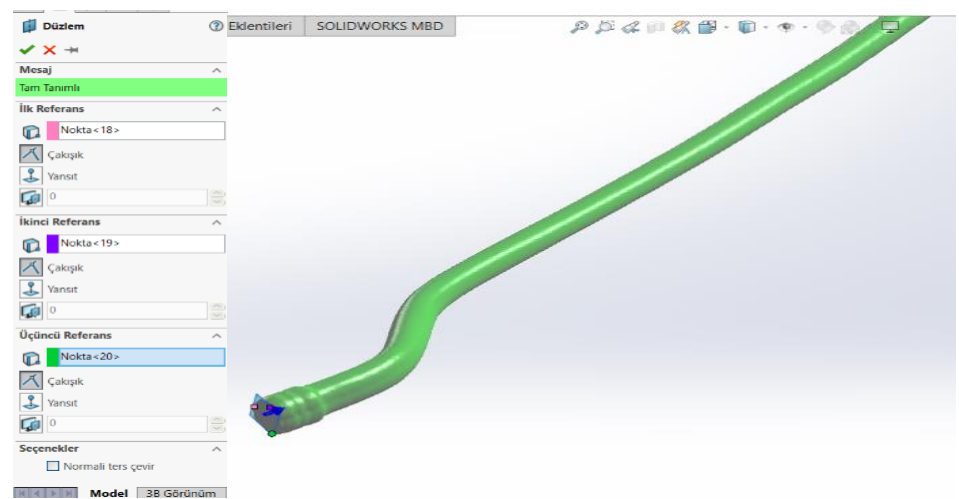

Şekil 9. Düzlem Oluşturma Penceresi ve düzlem oluşturma (Reference geometry window and creating of a plane)

Şekil 10'da eğri sihirbazı penceresi ve eğri sihirbazı modülündeki kesit komutuyla oluşturulan kesitler görülmektedir. Eğri sihirbazı modülü açılır, eğri sihirbazı penceresinde gizli, kesit, sınır komutlarından kesit komutu seçilir. Kesit alınmak istenilen düzlem ve kesitlerin başlangıç noktası belirlenir. Kesit alınmak istenilen düzlem belirlendikten sonra iki boyutlu, üç boyutlu kesit çizgileri program tarafından otomatik olarak oluşturulur. 

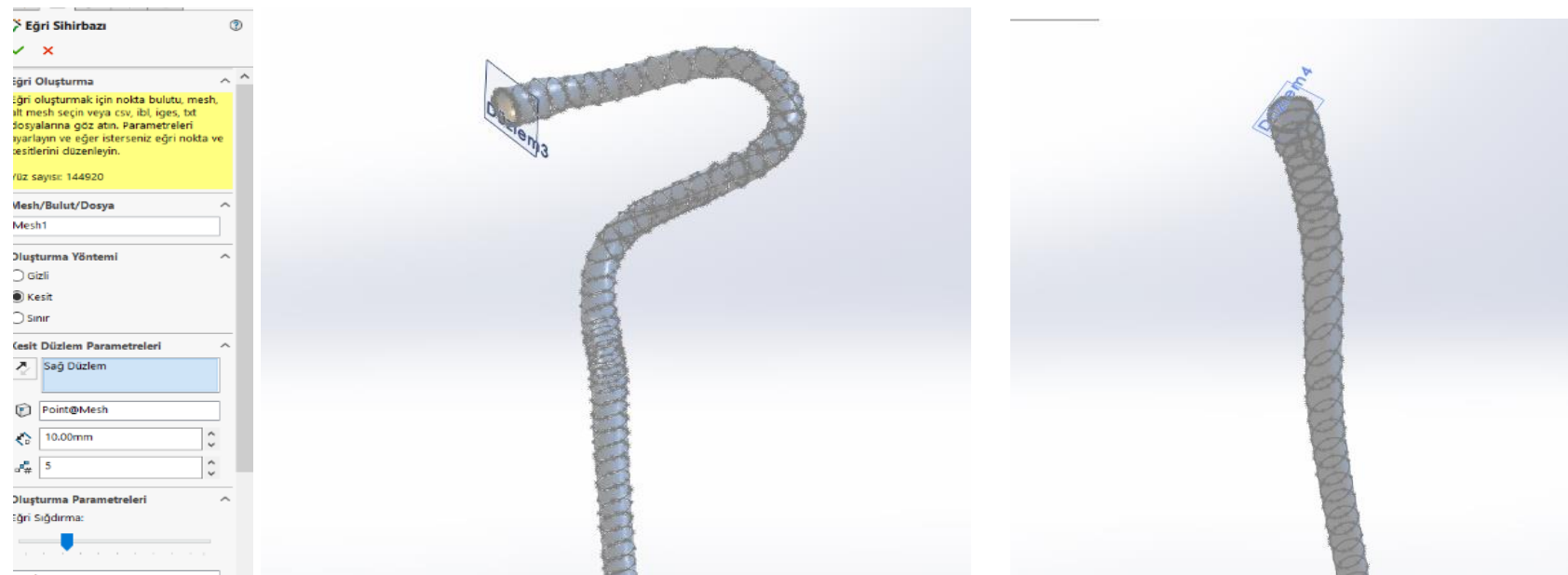

Şekil 10. Eğri sihirbazı penceresi ve modelden elde edilen kesitler (Curve wizard window and sections obtained from model)

Programda bulunan çizim ve yüzeyler modülleriyle gerekli düzenlemeler yapılmış, yüzey oluşturulmuş, modelin dataları elde edilmiştir. Şekil 11'de çalışma sonucu elde edilen yüzey verilmiştir. Çizim modüllerinden spline düzenleme komutlarıyla kesit çizgileri düzenlenmiştir. Yüzey modüllerinden loftlu yüzey komutuyla düzenlenmiş kesit çizgileri kullanılarak modelin yüzeyi oluşturulmuştur.

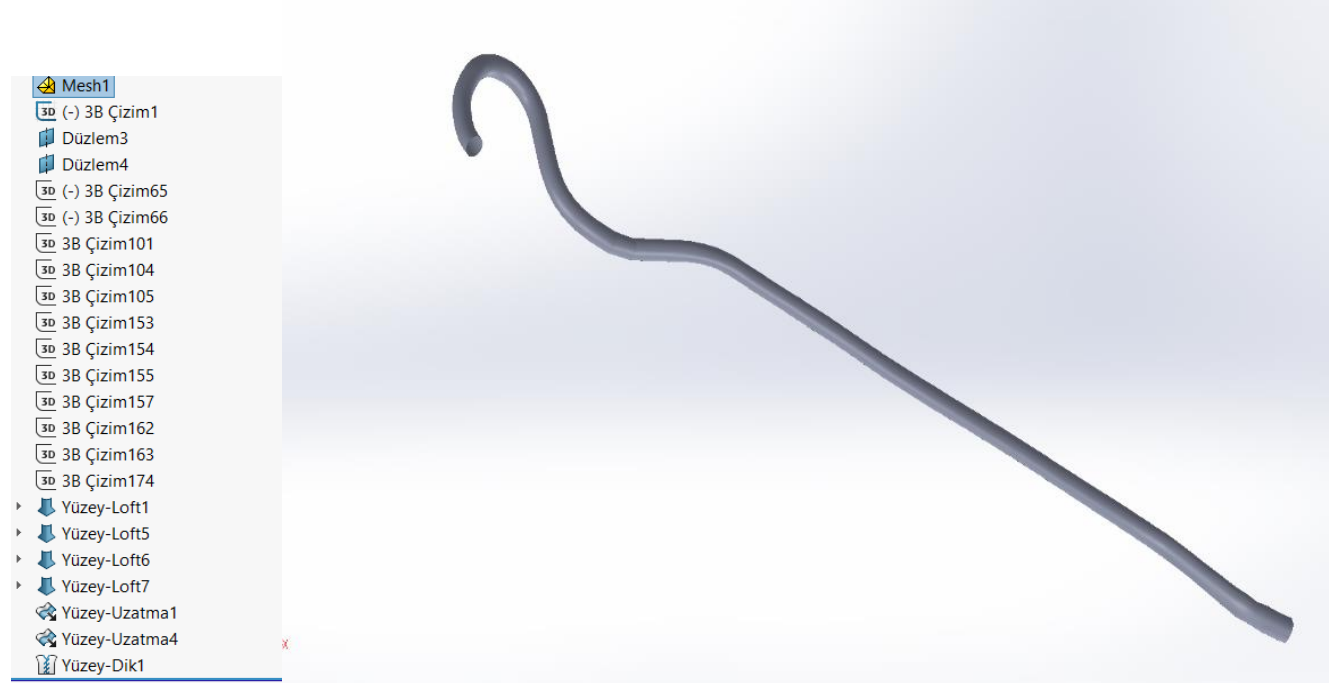

Şekil 11. Çalışma sonucunda oluşturulan yüzey (Created surface after the study)

\section{Yüzey Sihirbazı (Surface Wizard Property Manager)}

Scan to 3D eklentisindeki bu modül yüzey oluşturmak için kullanılır. Yüzey Sihirbazı Modülü iki farklı yüzey oluşturma seçeneği sunar. Bunlardan biri Otomatik Oluşturma seçeneği diğeri Yönlendirilmiş Oluşturma seçeneğidir. Otomatik Oluşturma seçeneğinde mesh yapı program tarafından otomatik olarak yüzeye dönüștürülür, manuel herhangi bir düzenleme yapılmasına olanak sağlamaz. Yönlendirilmiş Oluşturma komutunda, kullanıcı yüzey şekillerini düzenler ve programın verdiği geometrik yapılarla manuel olarak mesh yüzeyini kaplar. Yönlendirilmiş Oluşturma komutu içerisinde aynalama için Mesh Ayrımı, yüzey tanıma işlemlerine yüzey giydirilmesi için alt mesh gruplarına bölme işlemini yapan Yüz Tanıma ve belirlenen alt mesh gruplarına otomatik yüzey oluşturmak için Yüzey Çıkarılması seçenekleri kullanılır. Şekil 12'de bu Yönlendirilmiş Oluşturma komutunun alt komut pencereleri verilmiştir. 


Yüzey Sihirbazı
Mesh Ayrımı
Opsiyonel olarak meshi bölmek için bir
referans düzlemi kullanın. Meshi simetri
düzleminde bölmek çoğu zaman modelin
yalnızca yarısından yüzleri çıkartıp öbür
yarısını aynalayarak elde etmenize yarar.
Ayrık Düzlem
$\otimes$.

(a)

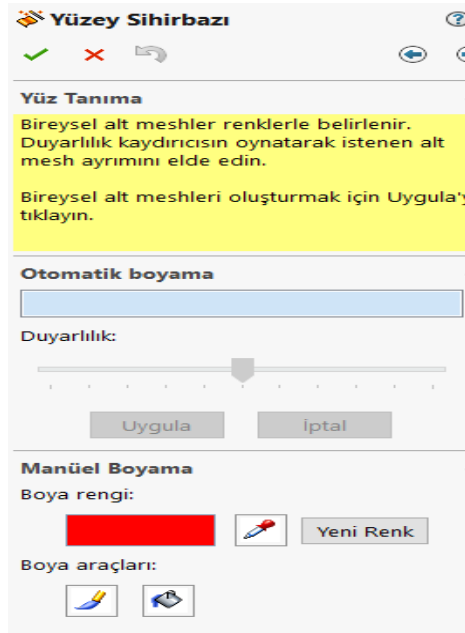

(b)

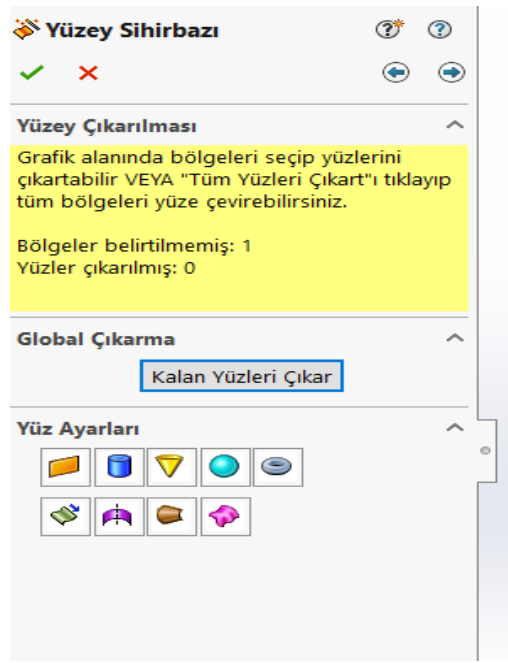

(c)

Şekil 12. Altkomut penceresi a. Mesh Ayrımı, b. Yüz Tanıma, c. Yüzey Çıkarma (a.Mesh Surface extraction property, b. Split Property, c. Face identification property)

\section{Sapma Analizi (Deviation Analysis)}

Scan to 3D eklentisindeki Sapma Analizi modülü üç boyutlu tarama ile elde edilen veri ile Scan to 3D eklentisi komutları kullanılarak oluşturulan katı modelin arasındaki sapmayı belirlemek için kullanılır. Şekil 13'de komutun kullanım penceresi ve sapma değerleri ekran görüntüsü verilmiştir. Uygulamalardaki uzmanlık, tecrübe ve parçanın kompleksliğine göre sapma oranları değişmektedir.

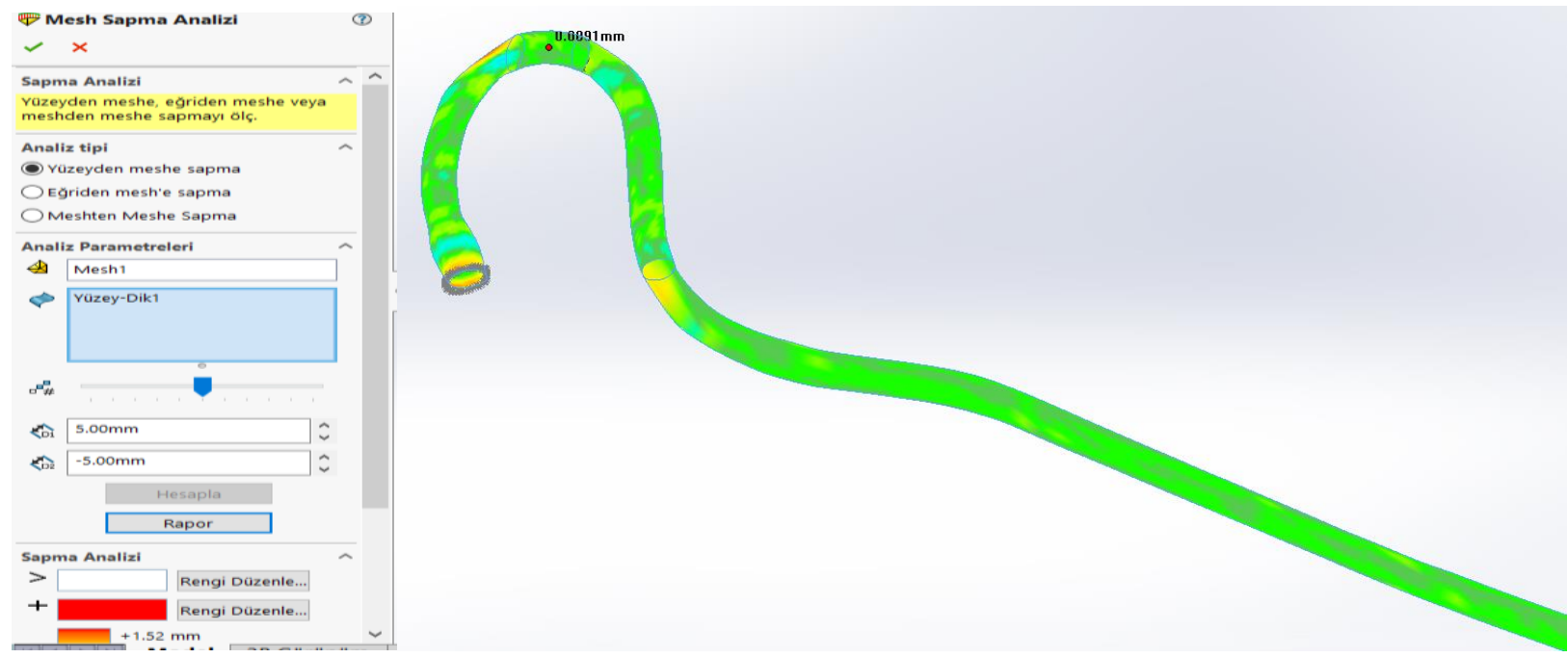

Şekil 13. Mesh Sapma Analizi komut penceresi ve parça üzerindeki uygulaması (Deviation Analysis command window and implemantation on part)

\section{Sonuç ve Tartışma (Result and Discussion)}

Tersine mühendislik uygulamaları için kullanılan Geomagic, Space Claim vb. gibi spesifik programlar mevcuttur. Bu programlar nokta bulutundan katı modele dönüşüm işlemlerini yapmaya olanak sağlamaktadır. Bu çalışmada ise belirlenen parçaların tarama dataları üzerinde tersine mühendislik uygulamalarının SolidWorks CAD programı ile yapılabilirliği araștırılmıștır.

Bu amaçla tersine mühendislik ihtiyacı duyulan bir araca ait eğrisel formlu yağ borusu üzerinde SolidWorks programının Scan to 3D eklentisinin mesh hazırlık sihirbazı, mesh düzenleme ve eğri sihirbazı komutları kullanılarak başarılı bir tersine mühendislik uygulaması yapılmıștır. Yüzey oluşturma işlemlerinde kullanılan yüzey sihirbazı komutu ise kullanılmamıştır. Çalışmada amaç yağ borusunun eğrisel formunun tersine mühendislik yoluyla elde edilmesidir. Taraması yapılan gerçek yağ borusunun çapı 10 mm'dir. Eğri sihirbazı ile elde edilen çemberlerin çaplarının kullanılan kesit düzlemlerine göre farklılık gösterdiği saptanmıştır. $\mathrm{Bu}$ doğrultuda eğri sihirbazı ile elde edilen çemberler parçanın eğrisel formunu oluşturmak için kullanılmıştır. Eğrisel 
formlu yağ borusunun çapı manuel olarak 10 mm girilmiştir. Kompleks ve detay içeren parçalarda ise daha yoğun çalışma ve tecrübe gerekmektedir.

Optik veya lazer tarama cihazlarından alınan ve stl veya ply formatındaki endüstriyel parçaların tarama dataları üzerinde SolidWorks CAD yazılımının Scan to 3D modülü ile tersine mühendislik ișlemlerinin yapılabileceği tespit edilmiştir. Çalışmada üzerinde çok fazla detay olmayan parçaların sorunsuz bir şekilde CAD dataları oluşturulabilmiştir. Endüstride tasarım için yaygın kullanılan SolidWorks, Catia, Unigraphics gibi CAD programları ile çok kompleks olmayan parçaların tarama dataları üzerinde tersine mühendislik çalışmalarının kolaylıkla yapılabileceği görülmüştür. Çok kompleks parçalar için ise tersine mühendislik için geliştirilen spesifik yazılımlar kullanılmalıdır.

\section{Çıkar Çatışması (Conflict of Interest)}

Yazarlar tarafından herhangi bir çıkar çatışması beyan edilmemiştir. No conflict of interest was declared by the authors.

\section{Teşekkür (Acknowledgements)}

Bu çalışmanın yapılmasında donanım ve yazılım altyapısını kullandığımız Kütahya Dumlupınar Üniversitesi İleri Teknolojiler Merkezi (DPÜ-İLTEM) ne teşekkürlerimizi sunarız.

\section{Kaynaklar (References)}

Çelebi, A., Tosun, H. ve Önçağ A.Ç. (2017). Hasarlı Bir Kafatasının Üç Boyutlu Yazıcı ile İmalatı ve İmplant Tasarımı, International Journal of 3D Printing Technologies and Digital Industry,1:1,27-35.

Çetinel, M. (2008). Tersine Mühendislik ile Üç Boyutlu Cisimlerden Grafik Model İçin Veri Elde Edilmesi, Yüksek Lisans Tezi, Yıldız Teknik Üniversitesi Fen Bilimleri Enstitüsü, İstanbul,142s.

Çifci, U., Özkan, A. ve Taşdemirci, Ç. (2019). Üç Boyutlu Yazıcı Teknolojilerinin Hızlı Prototip Uygulamaları için Farklı Materyaller Aracılığıyla Yüzey Pürüzlülüğüne Etkilerinin İncelenmesi, Düzce Üniversitesi Bilim ve Teknoloji Dergisi, 7(2019),1627-1643.

Demir, H. (2018). CAD Datası Olmayan Parçaların Tersine Mühendislik Metodu ile CAD Datalarının Oluşturulması, Yüksek Lisans Tezi, Fırat Üniversitesi Fen Bilimleri Enstitüsü, Elazı̆̆, 114s.

Eren, O., Sezer, H. K. Ve Börklü, H. R. (2018). Tersine Mühendislik Tasarımı: Endüstriyel Tasarım Mühendisliği Lisans Öğrencileri için Teknik Seçmeli Ders, Uluslararası 3B Yazıcı Teknolojileri ve Dijital Endüstri Dergisi, 2-3(2018), 1-11.

İşbilir F., Çelik B., Özsan, A. ve Kaynak M. F. (2018). Tersine Mühendislik Temelli Araç Üstyapı Tasarım, Analiz ve Üretiminin İncelenmesi, Sürdürülebilir Mühendislik Uygulamaları ve Teknolojik Gelişmeler Dergisi, 1(2), 72-79.

Kaplan, A. (2016). Francis Tipi Türbin Çarkının Tersine Mühendislik ile Tasarımı ve Rehabilitasyonu, Yüksek Lisans Tezi, Tobb Ekonomi ve Teknoloji Üniversitesi Fen Bilimleri Enstitüsü, İzmir, 102s.

Manmadhachary A., Ravi Kumar Y.ve Krishnanand L. (2016). Improve the Accuracy, Surface Smoothing and Material Adaption in STL File for RP Medical Models, Journal of Manufacturing Processes, 21(2016), 46-55.

Önçă̆, A. Ç., Tekcan, Ç. Ve Özden, H. (2017). Mekanik Parçaların Tersine Mühendislik ile Modellenmesinin Değerlendirilmesi ve Bir Uygulama, Pamukkale Üniversitesi Mühendislik Bilimleri Dergisi, 24(1), 43-49.

Sarı, M. İ. (2019). Tersine Mühendislik Yaklaşımı ile Antibakteriyel Antimikrobiyal Ortez Tasarımı ve İmalatı, Yüksek Lisans Tezi, Gazi Üniversitesi Fen Bilimleri Enstitüsü, Ankara, 98s.

Şahin, İ., Şahin, T., Gökçe, H. ve Eren, O. (2017). Hasarlı Dişlilerin Tersine Mühendislik Yaklaşımıyla Yeniden Oluşturulması, Düzce Üniversitesi Bilim ve Teknoloji Dergisi, 5(2017), 485-495. 